Marquette University

\title{
e-Publications@Marquette
}

College of Nursing Faculty Research and

Publications

Nursing, College of

8-9-2019

\section{Cross-Cultural Adaptation and Psychometrics Properties of the Arabic Version of the Positive Thinking Skills Scale}

\author{
Abir K. Bekhet \\ Marquette University, abir.bekhet@marquette.edu \\ Veronica Nakhla \\ Marquette \\ Isis Emile Gohar \\ Alexandria University \\ Rawan Oudeh \\ Marquette University \\ Mary Gergis \\ Towson University
}

See next page for additional authors

Follow this and additional works at: https://epublications.marquette.edu/nursing_fac

Part of the Nursing Commons

\section{Recommended Citation}

Bekhet, Abir K.; Nakhla, Veronica; Gohar, Isis Emile; Oudeh, Rawan; Gergis, Mary; and Malik, Nadia, "CrossCultural Adaptation and Psychometrics Properties of the Arabic Version of the Positive Thinking Skills Scale" (2019). College of Nursing Faculty Research and Publications. 633.

https://epublications.marquette.edu/nursing_fac/633 


\section{Authors}

Abir K. Bekhet, Veronica Nakhla, Isis Emile Gohar, Rawan Oudeh, Mary Gergis, and Nadia Malik 
Marquette University

e-Publications@Marquette

\title{
Nursing Faculty Research and Publications/College of Nursing
}

This paper is NOT THE PUBLISHED VERSION; but the author's final, peer-reviewed manuscript. The published version may be accessed by following the link in the citation below.

Issues in Mental Health Nursing, Vol. 41, No. 1 (2020): 49-53. DOI. This article is (C) Taylor \& Francis and permission has been granted for this version to appear in e-Publications@Marquette. Taylor \& Francis does not grant permission for this article to be further copied/distributed or hosted elsewhere without the express permission from Taylor \& Francis.

\section{Cross-Cultural Adaptation and Psychometrics Properties of the Arabic Version of the Positive Thinking Skills Scale}

\author{
Abir K. Bekhet \\ College of Nursing, Marquette University, Milwaukee, Wisconsin \\ Veronica Nakhla \\ College of Health Sciences, Marquette University, Milwaukee, Wisconsin \\ Isis Emile Gohar \\ Alexandria University, Alexandria, Egypt \\ Rawan Oudeh \\ Klinger College of Arts \& Sciences, Marquette University, Milwaukee, Wisconsin \\ Mary Gergis \\ Towson University, Towson, Maryland \\ Nadia Malik \\ College of Health Sciences, Marquette University, Milwaukee, Wisconsin
}




\section{Abstract}

\section{Abstract}

\section{Background}

Identifying depressive cognitions in first-generation Middle Eastern immigrants (FGMEI) can be an important step to prevent the development of clinical depression.

\section{Purpose}

This study focused on the cross-cultural equivalence and psychometric testing of the Arabic version of the Positive Thinking Skills Scale (A-PTSS) among 100 FGMEl.

\section{Methods}

Content/face validity of the measure was conducted. Internal consistency, homogeneity, dimensionality and construct validity were assessed.

Results

Cronbach's alpha for (A-PTSS) was .89. Factor extraction generated only one factor, which is consistent with the English version. The A-PTSS total score had a strong positive correlation with the positive cognition scores $(r=.42, p<.001)$, the total resourcefulness scores $(r=.39, p<.001)$, and with the total generalized anxiety scores $(r=-.42, p<.001)$, thereby suggesting construct validity.

\section{Conclusion}

This scale has the potential to become a useful screening tool for depressive cognitions among FGMEl.

\section{Introduction}

Middle Easterners are considered one of the most growing immigrant groups in the United States (US). A recent analysis by the Center for Immigration Studies revealed that the number of immigrants from the Middle East has jumped more than sevenfold between 1970 and 2000. More specifically, Middle Eastern immigrants were fewer than 200,000 in 1970 and they have reached nearly 1.5 million in 2000 (Camarota, 2002). Migrant studies in US have rarely covered the Middle Eastern population and they failed to distinguish between first and second generations (Nasseri \& Moulton, 2011).

\section{Statement of the problem}

First-generation migrants are facing enormous stress and they are at an increased risk of depression for a wide range of reasons including, but not limited to, language barriers, occupation, alienation, loneliness, culture shock, and home sickness. Worldwide, depression is the second leading cause of disability. Although the popular media increasingly reports on the rise of depression among Middle Eastern immigrants, reports of ways to intervene to stem that depression are limited. Detecting and treating early depressive thoughts in Middle Eastern immigrants can be an important step in preventing the development of clinical depression and suicide. In 2016, it was suggested that the use of culturally specific validated measurement tools for assessing migrant mental health is highly needed. As indicated by previous researchers, there is a necessity for clinicians and researchers to have reliable and valid scales in their own native language to measure a concept of interest (Sousa, Zauszniewski, Mendes, \& Zanetti, 2005). Positive thinking is a cognitive process that has been instrumental in assisting individuals to deal with problems and has been used as a useful strategy for coping with 
negative life situations, including depression (Bekhet \& Garnier-Villarreal, 2017). Therefore, a reliable and a valid measure that assesses both the negative and positive aspects of cognitions is needed. Specifically, assessing the depressive thinking that may precede the development of clinical depression that can be used with Middle Eastern immigrants is highly needed.

\section{Purpose}

The purpose of this study is to translate and test the psychometric properties of the Arabic version of the Positive Thinking Skills Scale (A-PTSS) among first-generation Middle Easterner immigrants (FGMEI).

\section{The Positive Thinking Skills Scale}

The Positive Thinking Skills Scale (PTSS) is an eight-item reliable and valid scale that measures the frequency of use of positive thinking skills (Bekhet \& Zauszniewski, 2013). The skills measured in the scale include cognitive activities to increase positive thoughts and to eliminate or modify negative ones. "Thus, the measure recognizes both negative and positive aspects of cognition while capturing the frequency with which respondents use the skills directed toward achieving positivity" (Bekhet \& Zauszniewski, 2013, p. 1078). Beck's cognitive theory of depression proposes that the depressive thoughts precede the development of clinical depression (Beck, Brown, Steer, Eidelson, \& Riskind, 1987). Therefore, early identification of the depressive thoughts is essential in preventing clinical depression and the costs associated with it. A cutoff score of 13 on the PTSS was determined to be the point at which referral and/or intervention would be suggested (Bekhet \& GarnierVillarreal, 2017). Consequently, this can help in the early identification of depressive symptoms that might develop because of the daily stressors and life challenges faced by FGMEI. The PTSS is four-point Likert scale with scores range from 0 to 24 . Higher scores indicate higher frequency of use of positive thinking skills by participants. The PTSS is reliable as indicated by a Cronbach's alpha of .90 $(\alpha=.90)$. Criterion validity was supported by significant correlations with positive cognitions and resourcefulness in the expected direction ( $r s=.53 ; .63 p<.01$ respectively) (Bekhet \& Zauszniewski, 2013). The PTSS is unique among others as it is a brief measure that takes only 5 minutes to complete and is a direct measure of intervention fidelity to skills that may be taught to FGMEI during a positive thinking training. This measure can be used for assessing the skills used by FGMEI and can be used to evaluate the frequency of using them. The psychometric properties of the PTSS among 131 American college students have been assessed in a recent study conducted by Matel-Anderson and Bekhet (2019). The results indicated internal consistency, and construct validity was supported for the PTSS as indicated by a Cronbach's alpha of .86 and significant correlation with measures of suicide resilience, perceived social support and self-esteem (Matel-Anderson \& Bekhet, 2019). In addition, all the items loaded cleanly on one factor and explained $59 \%$ of the variance (Matel-Anderson \& Bekhet, 2019). The results of another study indicated that the PTSS is a reliable scale as indicated by a Cronbach's alpha of .89 in sample of 128 acute care nurses. The PTSS has been translated into the Turkish language, and its psychometric properties assessed in 295 university students. The confirmatory factor analysis of the Turkish version indicated that all items loaded on one factor and Cronbach's alpha was .87. All these previous results demonstrate that this scale is a valid and reliable instrument (Akin, Uysal, \& Akin, 2015). 


\section{Methods}

\section{Design}

A cross-sectional descriptive design was used to translate and test the psychometric properties of the Arabic version of the Positive Thinking Skills Scale (A-PTSS) among Middle Easterners (ME) firstgeneration immigrants.

\section{Sample}

The sample included $100 \mathrm{FGMEI}$. To be included in the study, immigrants need to be first generation immigrants, 18 years and older, and who can read and write in Arabic. No potential participants were excluded on the basis of gender or socioeconomic status.

\section{Data collection procedure}

The $\mathrm{PI}$ and the research assistants contacted the religion leaders of the church and the Mosques (the priest and the Imam) to explain the purpose of the study and to ask for their help in recruiting the subjects. The IRB-approved flyers were distributed at the church and the mosques with the contact information of the researcher assistants. Interested subjects contacted the research assistants, and the questionnaire was distributed to participants who are interested either before or after the religious services at their convenience. The researcher assistants distributed the questionnaires and double checked each questionnaire in order to minimize missing data. Participants were given a \$15 gift cards to thank them for participation. All data provided by study participants were assigned an arbitrary code number rather than using their name or other information that could identify them as an individual. No names were on data collection instruments. To keep everything completely anonymous, the written consent was replaced with an information sheet, which basically just takes off the signature portion at the end of the consent and replaces it with language to the effect that by filling out the questionnaires conveys consent to be a participant in this research.

\section{Variables and measures}

Generalized Anxiety Disorder 7 (GAD-7) is a self-reported questionnaire for screening and measuring the severity of generalized anxiety disorder. GAD-7 has seven items, which measure severity of various signs of GAD on a four-point Likert scale ranging from 0 "not at all sure" to 4 "nearly everyday." Example of the scale items is "Over the last 2 weeks, how often have you been bothered by the following problems; Feeling nervous, anxious, or on edge." The scale is reliable as indicated by a Cronbach's alpha of .92. Test-retest reliability was also supported by intraclass correlation of .83 (Spitzer, Kroenke, Williams, \& Lowe, 2006).

Positive cognitions were measured by the eight-item Depressive Cognition Scale (DCS), which measures positive cognitions when scores are not reversed as all items are phrased in a positive direction. Scores range from 0 to 40 on a six-point Likert scale ranging from $0=$ strongly disagree to 5 = strongly agree (Zauszniewski, 1995). Reliability of the scale was indicated by Cronbach's alphas ranging from .75 to .87 (Zauszniewski et al., 2002; Zauszniewski \& Suresky, 2010). Construct validity was indicated by correlations with measures of burden and resourcefulness $(r s=-.40, .65$, respectively). Confirmatory factor analysis yielded a single factor that explained $48 \%$ of the variance (Zauszniewski \& Suresky, 2010). 
The Arabic version of the DCS (A-DCS) is also reliable and valid. Cronbach's alpha for (A-DCS) was .86 in first-year adolescent Egyptian nursing students (Bekhet \& Zauszniewski, 2010). Also, the Cronbach's alpha for A-DCS in Egyptian older adults was .89 (Bekhet, Fouad, \& Zauszniewski, 2011). Construct validity was also supported for (A-DCS) as indicated by a strong positive correlation with a total score of the Alienation Scale scores $(r=.51, p<.01)$. Like the English version, the factor extraction produced only one factor that explained $49.95 \%$ of the variance in the items of the scale (Bekhet $\&$ Zauszniewski, 2010).

Resourcefulness was measured by the 28 -item resourcefulness scale which measures both personal (16 items) and social resourcefulness (12 items) on a six-point Likert scale ranging from $0=$ extremely non-descriptive to $5=$ extremely descriptive. Reliability is indicated by a Cronbach's alpha of .85. The substantial intercorrelations between the two factors (personal and social resourcefulness) further supported the scale's construct validity (Zauszniewski, Eggenschwiler, Preechawong, Roberts, \& Morris, 2006).

\section{Data analysis}

Descriptive statistics were used to assess the demographics and main study variables. In order to determine the internal consistency and homogeneity of the A-PTSS, Cronbach's alpha coefficient, interitem correlations, and item-to-total correlations were assessed. Furthermore, scale dimensionality and construct validity were assessed by conducting factor analysis. Also, construct (convergent) validity were assessed by examining the correlation between the total scores on the A-PTSS and measures of positive cognitions, resourcefulness, and anxiety.

\section{Results}

\section{Characteristics of the study sample}

The sample included 100 first-generation Middle Eastern immigrants who were recruited from Middle Eastern churches and mosques in Milwaukee, WI. The mean age of participants was 46.5 years $(S D=.14 .2)$. The number of years spent in the USA ranged from a year to 49 years with a mean of 18 years. Fifty-one percent were Christians, and forty-nine were Moslems. Regarding gender, 68\% were females and $32 \%$ were males. The sample included diverse country of origin; $42 \%$ were Egyptians, $28 \%$ were Palestinians, $15 \%$ were Jordanian, and the remaining $15 \%$ were from Syria, Iraq, Sudan, Algeria, Lebanon, Kuwait, and Oman. Regarding education, $46 \%$ had college education, $17 \%$ had graduate/professional training, $21 \%$ had high-school diploma or some college/associated degree, and $16 \%$ had less than 7 years of school or some high-school education. Twenty-six percent reported an income between 5,000 and less than 15,000 a year. Sixty-one percent reported an income between 15,000 and 40,000 a year, and $39 \%$ percent reported an income of 45,000 or more. Eighty-one percent were married, $10 \%$ were divorced or widowed, and $9 \%$ were never married.

\section{Content/face validity of the measure}

Consistent with the literature, the process of translation begins with a fluent bilingual professor who translated the English version of the PTSS into an Arabic version (A-PTSS) (Bekhet \& Zauszniewski, 2010; Yu, Lee, \& Woo, 2004). Following the translation of the measure, a blind backtranslation was completed, during which two other bilingual experts converted the translated instrument (A-PTSS) into the original English language without having seen the original instrument 
(Bekhet \& Zauszniewski, 2010; Brislin, 1986; Yu et al., 2004). As necessary, revisions were made, and discrepancies were examined between the PTSS and the A-PTSS until the two forms appeared to be equivalent, which is the most reliable method in determining cultural equivalence of an instrument. As indicated in the literature equivalence likely to be achieved when both language versions of an instrument are identical in meaning (Sousa et al., 2005). A panel of three Arabic bilingual professors reviewed the translations, grammar, and structure of the A-PTSS by comparing the English and the Arabic versions to ensure consistency. After reaching a consensus regarding consistency, grammar, and structure, an Arabic version of the PTSS (A-PTSS) was produced.

Cross-Cultural Equivalence Analysis.

Investigation of the symmetrical translations and back-translations of the PTSS showed lack of consistency on one of the scale items. For example, one translator translated the item, "Note the need

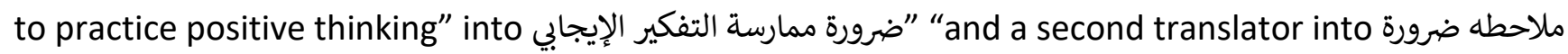
مack translations of this item were "Need to practice positive thinking" and "Note the need to practice positive thinking" The panel of three Arabic bilingual members compared the original scale and two translated versions into Arabic to validate the translation. The Arabic version of the scale that Arabic panel members agreed as the one with best semantic equivalence was further reviewed and edited to meet the requirements of Arabic grammar and structure. The final item became ملاحطه ضرورة ممارسة التفكير الإيجابي.

\section{Internal consistency and homogeneity}

The overall estimate of the reliability of the A-PTSS (Cronbach's alpha) was .89 and exceeded the recommended criteria. As recommended in the literature, at least .70 is required for a newly developed scale (Nunnally \& Bernstein, 1994). Deletion of any one of the items of the A-PTSS did not improve the overall Cronbach's alpha coefficient for the scale. As shown in Table 1, item-to-total score correlations were between $r=.30$ and $r=.70$, meeting the required criteria for scale homogeneity except for item \# 7 (.74), where it is slightly higher than .70 (Ferketich, 1991). As shown in Table 2, 96\% of the inter-item correlations were between $r=.30$ and $r=.70$, indicating internal consistency and that the scale measures diverse aspects of positive thinking (Nunnally \& Bernstein, 1994).

Table 1. The Arabic version of the PTSS item analysis and factor analysis.

\begin{tabular}{|l|l|l|l|l|}
\hline Item & Alpha if item deleted & Item-to-total score correlation & Factor loadings & Communality values \\
\hline PTSS 1 & .87 & .67 & .76 & .58 \\
\hline PTSS 2 & .87 & .64 & .72 & .52 \\
\hline PTSS 3 & .88 & .61 & .71 & .50 \\
\hline PTSS 4 & .87 & .69 & .77 & .60 \\
\hline PTSS 5 & .88 & .55 & .64 & .42 \\
\hline PTSS 6 & .87 & .69 & .78 & .60 \\
\hline PTSS 7 & .86 & .74 & .83 & .68 \\
\hline PTSS 8 & .87 & .68 & .77 & .60 \\
\hline
\end{tabular}

Table 2. The Positive Thinking Skills Scale inter-item correlation matrix.

\begin{tabular}{|l|l|l|l|l|l|l|l|l|}
\hline Item & 1 & 2 & 3 & 4 & 5 & 6 & 7 & 8 \\
\hline 1 & & .44 & .53 & .63 & .37 & .50 & .57 & .50 \\
\hline
\end{tabular}




\begin{tabular}{|l|l|l|l|l|l|l|l|l|}
\hline 2 & & & .42 & .50 & .55 & .52 & .52 & .44 \\
\hline 3 & & & & .48 & .34 & .43 & .54 & .50 \\
\hline 4 & & & & & .47 & .53 & .57 & .46 \\
\hline 5 & & & & & & .50 & .38 & .37 \\
\hline 6 & & & & & & & .57 & .58 \\
\hline 7 & & & & & & & & .74 \\
\hline
\end{tabular}

Table 3. Construct validity.

\begin{tabular}{|l|l|l|l|l|}
\hline & A-PTSS & A-DCS & A-RS & A-GAD-7 \\
\hline A-PTSS & 1 & & & \\
\hline A-DCS & $.42^{*}$ & 1 & & \\
\hline A-RS & $.39^{*}$ & $.29^{*}$ & 1 & \\
\hline A-GAD-7 & $-.42^{*}$ & $-.44^{*}$ & $-.38^{*}$ & 1 \\
\hline
\end{tabular}

Note. A-PTSS $=$ The Arabic version of the Positive Thinking Skills Scale; A-DCS $=$ The Arabic version of the Depressive Cognition Scale which measures positive cognitions when scored are not reversed; A$\mathrm{RS}=$ The Arabic version of the Resourcefulness Scale; GAD-7 = the Arabic version of the Generalized Anxiety Disorder 7 item scale.

$* p<.001$

\section{Dimensionality and construct validity}

The Kaiser-Meyer-Olkin value of .89 also indicated that the sample size was adequate to proceed with factor analysis as it exceeded the recommended value of .60 (Tabachnick \& Fidell, 2001). Bartlett's test of sphericity was significant $(\chi 2=365.37 ; p<.001)$, indicating that the correlation matrix was appropriate for factor analysis (Strickland, 2003). A principal component factor analysis was conducted on the Arabic version of the PTSS items to extract the minimum number of factors that explained the maximum variance in the items of the scale. As shown in previous studies, it was expected in this study that only one factor would emerge from factor analysis (Akin, Uysal, \& Akin, 2015; Bekhet \& Zauszniewski, 2013; Matel-Anderson \& Bekhet, 2019; Tully, 2016). In fact, the factor extraction generated only one factor with eigenvalue greater than 1 . The scree plot also clearly suggested that only one dimension underlay the items of the scale. As shown in Table 1, a single extracted factor explained $56 \%$ of the variance in the items of the scale. Thus, factor rotation was not needed. All communality values were above .30, as recommended by Tabachnick and Fidell (2001), and all items of the scale had strong factor loadings on the single factor that emerged, exceeding the minimum recommended criterion of .30 (Nunnally \& Bernstein, 1994; Polit, 1996).

The Arabic version of the PTSS total score had a strong positive correlation with the positive cognition scores $(r=.42, p<.001)$ indicating convergent validity. Also, the PTSS total score had a strong correlation with the total resourcefulness scores $(r=.39, p<.001)$, and with the total generalized anxiety scores $(r=-.42, p<.001)$, thereby suggesting construct validity or discriminant validity. These correlations indicating that the more the positive thinking, the more the resourcefulness for participants and the less the anxiety scores. 


\section{Discussion}

This study represents the first attempt to examine the reliability and the validity of the Arabic version of the Positive Thinking Skills Scale (A-PTSS) among first-generation Middle-Eastern immigrants (FGMEI). The results provide solid support for the scale's reliability and validity among FGMEI. Reliability was demonstrated through adequate estimates of internal consistency; Cronbach's alpha was .89, which exceeds the minimum criterion of .70 (Nunnally \& Bernstein, 1994). This internal consistency estimate is consistent with findings from other studies of PTSS measures, which reported an alpha of .90 in a sample of caregivers of persons with autism spectrum disorders (ASD) (Bekhet \& Zauszniewski, 2013). Also, alphas of .86, .87, and .89, respectively, were reported for the PTSS in a sample of 295 Turkish university students, 128 American acute care nurses, and 131 US college students (Akin et al., 2015; Matel-Anderson, Bekhet, \& Garnier-Villarreal, 2018; Tully, 2016). In this study, $88 \%$ of the corrected item-to-total correlations were within the recommended range of .30 to .70. In other words, seven of the eight (A-PTSS) were correlated with the total score in the optimal range between .30 and .70 , suggesting the homogeneity of the measure and that each item was measuring a unique construct and meeting the necessary criteria for scale homogeneity. The only item that exceeded the .70 criteria in this study of FGMEI was "Nurture ways to challenge pessimistic thoughts." This item was also the strongest in the factor analysis, indicating that nurture ways to challenge pessimistic thoughts was of greatest concern to FGMEI. FGMEI finding is also consistent with findings from a study of the measure of the PTSS in American college students (Matel-Anderson \& Bekhet, 2019). More specifically, in their study they found that $89 \%$ of the 28 possible inter-item correlations fell within the desired range (Matel-Anderson \& Bekhet, 2019).

In addition to providing evidence of the reliability of the A-PTSS, the findings indicate that the measure has construct validity, as evidenced by significant correlations in the expected direction with an established measure of positive cognitions, resourcefulness, and generalized anxiety disorder $(r=.42$, .39 , and $-.42 ; p<.001$, respectively) (Table 3 ). The findings of this study are consistent with the findings with previous studies, which found a significant with positive cognitions, resourcefulness, depression, and general well-being in a sample of 109 of caregivers of persons with ASD $(r=.53, .63,-$ .45 , and .40; $p<.01$, respectively) (Bekhet \& Zauszniewski, 2013).

The findings of the factor analysis provide further support for the construct validity of the A-PTSS. The emergence of a single factor that explained a substantial portion of the variance is consistent with factor analytic studies of the A-PTSS (Bekhet \& Zauszniewski, 2013; Matel-Anderson \& Bekhet, 2019). The variance explained in this study $(56 \%)$ is similar to some extent to the variance explained in previous study of caregivers of persons with ASD (59\%) (Matel-Anderson et al., 2018) and more than the variance explained in the study of college students (50\%) (Matel-Anderson \& Bekhet, 2019). However, it should be noted that the population is different in this study than the two mentioned studies. The greater amount of variance may be due to the fact that first-generation Middle Eastern immigrants constitute a more homogeneous population.

The findings of this study of the psychometric properties of the A-PTSS in FGMEI showed promising evidence that the 8-item A-PTSS has acceptable reliability and validity. Also, the findings pointed out the fact that the A-PTSS is potentially useful for assessing depressive thoughts that precede the development of clinical depression in FGMEI, which is vital for early detection and intervention. 
Further psychometric testing of the A-PTSS may be warranted. This study provides evidence that the APTSS consists of a single dimension and supports the construct validity of the A-PTSS for this sample of first-generation Middle Eastern immigrants.

\section{Disclosure statement}

No potential conflict of interest was reported by the authors.

\section{Reference}

Akin, A., Uysal, R., \& Akin, U. (2015). The validity and reliability of Turkish version of the Positive Thinking Skills Scale. Journal of European Education, 5(2), 16-22.

Beck, A. T., Brown, G., Steer, R. A., Eidelson, J. I., \& Riskind, J. H. (1987). Differentiating anxiety and depression: A test of the cognitive content specificity hypothesis. Journal of Abnormal Psychology, 96(3), 179-183.

Bekhet, A. K., \& Garnier-Villarreal, M. (2017). The Positive Thinking Skills Scale: A screening measure for early identification of depressive thoughts. Applied Nursing Research, 38, 5-8. doi: 10.1016/j.apnr.2017.08.004

Bekhet, A., Fouad, R., \& Zauszniewski, J. A. (2011). The role of positive cognitions in Egyptian elders relocation adjustment. Western Journal of Nursing Research, 33(1), 121-135. doi: 10.1177/0193945910381763

Bekhet, A., \& Zauszniewski, J. A. (2010). Psychometric properties of the Arabic version of the Depressive Cognition Scale in first-year adolescent Egyptian nursing students. Journal of Nursing Measurement, 18(3), 143-152. doi: 10.1891/1061-3749.18.3.143

Bekhet, A. K., \& Zauszniewski, J. A. (2013). Measuring use of positive thinking skills: Psychometric testing of a new scale. Western Journal of Nursing Research, 35(8), 1074-1093. doi: 10.1177/0193945913482191

Brislin, R. W. (1986). The wording and translation of research instruments. In W. J. Lonner \& J. Berry (Eds.), Field methods in cross-cultural research (pp. 137-164). Beverly Hills: Sage Publications.

Camarota, S. A. (2002). Immigrants from the Middle East: A Profile of the Foreign-born Population from Pakistan to Morocco. Center for Immigration Studies. Retrieved from http://www.cis.org

Ferketich, S. (1991). Focus on psychometrics. Aspects of item analysis. Research in Nursing \& Health, 14(2), 165-168.

Matel-Anderson, D., Bekhet, A. K., \& Garnier-Villarreal, M. (2018). Mediating effects of positive thinking and social support on suicide resilience. Western Journal of Nursing Research, 41(1), 25-41. doi:10.1177/0193945918757988

Matel-Anderson, D., \& Bekhet, A. K. (2019). Psychometric properties of the Positive Thinking Skills Scale among college students. Archives of Psychiatric Nursing, 33(1), 65-69. doi: 10.1016/j.apnu.2018.10.005

Nasseri, K., \& Moulton, L. H. (2011). Patterns of death in the first and second generation immigrants from selected Middle Eastern countries in California. Journal of Immigrant and Minority Health, 13(2), 361-370. doi: 10.1007/s10903-009-9270-7

Nunnally, J. C., \& Bernstein, I. H. (1994). Psychometric theory (3rd ed.). New York: McGraw-Hill. Polit, D. F. (1996). Data analysis and statistics for nursing research. Stamford: Appleton \& Lange. 
Sousa, V. D., Zauszniewski, J. A., Mendes, I. A., \& Zanetti, M. L. (2005). Cross-cultural equivalence and psychometric properties of the Portuguese version of the Depressive Cognition Scale. Journal of Nursing Measurement, 13(2), 87-99. doi: 10.1891/jnum.2005.13.2.87

Spitzer, R. L., Kroenke, K., Williams, J. B. W., \& Lowe, B. (2006). A brief measure for assessing generalized anxiety disorder: The GAD-7. Archives of Internal Medicine, 166(10), 1092-1097. doi: 10.1001/archinte.166.10.1092

Strickland, O. L. (2003). Using factor analysis for validity assessment: Practical considerations. Journal of Nursing Measurement, 11, 203-205.

Tabachnick, B. G., \& Fidell, L. S. (2001). Using multivariate statistics (4th ed. ). Needham Heights: Allyn \& Bacon.

Tully, S. (2016). Positive thinking and the perception of work-related stress in acute care nurses (Unpublished dissertation).

Yu, D. S. F., Lee, D. T. E., \& Woo, J. (2004). Issues and challenges of instrument translation. Western Journal of Nursing Research, 26(3), 307-320. doi: 10.1177/0193945903260554

Zauszniewski, J. A. (1995). Development and testing of a measure of depressive cognition in older adults. Journal of Nursing Measurement, 3(1), 31-41. doi: 10.1891/1061-3749.3.1.31

Zauszniewski, J. A., Eggenschwiler, K., Preechawong, S., Roberts, B. L., \& Morris, D. L. (2006). Effects of teaching resourcefulness skills in elders. Aging and Mental Health, 10(4), 1-9.

Zauszniewski, J. A., McDonald, P. E., Krafcik, K., Chung, C., Dobratz, M. C., \& Downe-Wamboldt, B. (2002). Acceptance, cognitions, and resourcefulness in women with diabetes. Western Journal of Nursing Research, 24(7), 728-743. doi: 10.1177/019394502762476951

Zauszniewski, J. A., \& Suresky, J. M. (2010). Psychometric assessment of the Depressive Cognition Scale in women family members of adults with serious mental illness. Issues in Mental Health Nursing, 31(7), 483-490. doi: 10.3109/01612841003602687

\section{Additional information}

\section{Funding}

The study was funded by the 2017 International Research Award by Marquette University 